\title{
ENTRE VÊNIAS E VELAS: DISPUTA POLÍTICA E CONSTRUÇÃO DA MEMÓRIA DO PADROEIRO DE SALVADOR (1686-1760)
}

\author{
Evergton Sales Souza \\ Professor adjunto do Departamento de História da Universidade Federal da Bahia.
}

\begin{abstract}
Resumo
Resultado parcial de uma pesquisa que deseja compreender as razões do fracasso devocional do culto ao padroeiro de Salvador - São Francisco Xavier -, o presente artigo descreve e analisa as tentativas de popularização da devoção, além de tratar dos interesses que nortearam a atitude de diferentes agentes em relação às celebrações dedicadas ao santo patrono. Ao estudar os conflitos políticos relacionados à organização das cerimônias e a construção da memória da suposta intercessão salvífica do navarrês quando da epidemia que assolou a cidade da Bahia, em 1686, pretende-se contribuir para a compreensão de aspectos relevantes da história política e religiosa do Brasil moderno.
\end{abstract}

\section{Palavras-chave}

culto aos santos $\bullet$ memória $\bullet$ conflitos políticos.

\section{Abstract}

This article presents partial results of a research that studies the reasons for the devotional failure of the cult of São Francisco Xavier, the patron saint of Salvador, describing and analyzing the attempts to popularize the devotion, as well as the interests of different agents relating to the celebrations of the saint. Studying political conflicts related to the organization of the ceremonies and the memory building of the supposed salvific intercession of the Navarrian during the 1686 epidemics that took over the city of Bahia, the intention is to contribute to the understanding of relevant aspects of the political and religious history of modern Brazil.

\section{Keywords}

cult of the saints $\bullet$ memory $\bullet$ political disputes.

\footnotetext{
O presente estudo é resultado parcial de pesquisas realizadas com apoio do CNPq e da Fapesb. Agradeço às bolsistas Pibic Camila T. Amaral, Ediana F. Mendes e Rebeca C. S. Vivas pela valiosa colaboração no levantamento e transcrição de parte das fontes aqui utilizadas.
} 
Em 10 de maio de 1686, por ocasião de uma epidemia de febre amarela - conhecida, então, por mal da bicha -, a Câmara de Salvador fizera voto de tomar S. Francisco Xavier como padroeiro, rogando-lhe que livrasse a cidade do mal que nela se abatia. ${ }^{1}$ A doença, entretanto, seguiu fazendo grande número de vítimas até meados de junho, não obstante a realização de várias procissões e deprecações que pediam auxílio a outros santos conhecidos por suas qualidades antipestilenciais. Em estudo anterior sobre as origens da eleição do padroeiro em Salvador, mostramos que os testemunhos da época não corroboram a ideia, que chegou até nossos dias, de que o fim da epidemia teria ocorrido devido à imediata intercessão do Apóstolo da Índia. ${ }^{2}$ O presente trabalho é, em alguma medida, uma continuidade do referido estudo. Após ter demonstrado que os atores da época não imputaram à intercessão do santo o cessar do mal da bicha, tentaremos, aqui, analisar alguns momentos fundamentais no processo de construção da memória acerca do papel desempenhado pelo santo jesuíta na ocasião. Trata-se de compreender como, no século XVIII, buscou-se legitimar a escolha do padroeiro e estabelecer um verdadeiro culto em torno de sua figura. Para tanto, é preciso indagar sobre instituições, grupos sociais e personagens envolvidos nesta história. De sua ação deriva, necessariamente, o sucesso ou insucesso da festa. É também de sua ação que emerge a empresa de reconstrução da memória em torno dos eventos que levaram à eleição do santo padroeiro. E é na observação das posições assumidas por cada um desses agentes que se

1 Em 1699, a cidade da Bahia era, no dizer de DAMPIER, William. A new voyage round the world. Londres: J. Knapton, 1703, p. 49-50, “a mais importante de todas as cidades do Brasil, seja pela beleza de suas construções e sua grandeza, seja pelo seu comércio e rendas”. Segundo a relação ad limina de d. João Franco de Oliveira, de julho de 1695, a cidade tinha cerca de cinco mil casas, sendo habitada por cerca de vinte mil civibus catholicis (cf. Archivio Segretto Vaticano, Sacræ Congregatione Concilii, Relationes, 712). Os números são, entretanto, bastante aproximativos. Dampier, por exemplo, afirmou que a cidade teria cerca de duas mil casas. D. António Luís de Sousa Tello e Menezes, segundo marquês das Minas, que era governador e capitão geral do Estado do Brasil, à época da epidemia, relatou que o número de mortos pela bicha teria chegado a 900 e teriam sido 25 mil os que contraíram a doença (cf. AHU. Códices I, cód. 252, fl. $107 \mathrm{v}^{0}$ e $108 \mathrm{r}^{\circ}$ ). Números provavelmente exagerados, mas que dão uma ideia de sua percepção sobre a dimensão da epidemia. Para uma visão de conjunto sobre a cidade da Bahia entre fins do século XVII e primeira metade do século XVIII ver BOXER, Charles R. A idade de ouro do Brasil. Dores de crescimento de uma sociedade colonial. Rio de Janeiro: Nova Fronteira, 2000, p. 153-187, capítulo "Bahia de Todos os Santos".

2 SALES SOUZA, Evergton. São Francisco Xavier, padroeiro de Salvador. Gênese de uma devoção impopular, Brotéria. Revista de Cultura, v. 163, p. 653-670. 
percebe a irrupção do político no que poderia ser tomado, erroneamente, como uma questão estritamente religiosa.

Liturgias não são traços exclusivos da religião. O poder tem as suas. E nelas imbricam-se sacralidade e política. ${ }^{3}$ Ao tornar-se pública, a manifestação religiosa ganha contornos que extrapolam os limites das formas de piedade e de expressão do sentimento religioso. Na procissão, bem como na missa em homenagem ao padroeiro, desenrola-se um teatro no qual os atores se veem uns aos outros e querem ser notados pelo público. Da posição ocupada na cena por cada ator ou grupo dependerá a percepção que a assistência terá de sua importância política e social. Nesta chave devem ser entendidas as lutas por vênias e velas, que constituem assunto da primeira parte deste artigo. Na segunda parte, fazendo uso de diferentes testemunhos, procura-se discernir o caminho de construção de uma memória que dotou nosso padroeiro, S. Francisco Xavier, de um milagre jamais operado. ${ }^{4}$

3 Há uma imensa bibliografia sobre o assunto. Entre historiadores, estudos como os de Ernst Kantorowicz e Ralph Giesey norteiam a abordagem cerimonialista do poder. Uma importante crítica desta corrente historiográfica pode ser vista em BOUREAU, Alain. Le simple corps $d u$ roi. L'impossible sacralité des souverains français XV $\mathrm{V}^{\mathrm{e}}$-XVIII ${ }^{\mathrm{e}}$ siècles. Paris: Editions de Paris, 1988 e Les cérémonies royales françaises entre performance juridique et compétence liturgique. Annales, vol. 46, n. 6, 1991, p. 1.253 - 1.264. Trabalhos antropológicos também contribuíram bastante para o avanço dos estudos neste campo, destacando-se aí autores como Luc de Heusch, Victor Turner e Clifford Geertz. Entre historiadores dedicados ao estudo do mundo português moderno, Fernando Bouza-Álvarez e Diogo Ramada Curto produziram trabalhos que serviram de inspiração a muitos que, posteriormente, se interessaram por este tipo de abordagem da história política. Estudos como os de Pedro Cardim, Ana Paula Meggiani e Beatriz Catão são exemplos da continuidade desse interesse. Por último, gostaria de referir à obra, ainda pouco conhecida entre nós, mas de importância singular para estudos como este que ora apresentamos, de MÁRQUEZ, Jaime Valenzuela. Las liturgias del poder. Celebraciones públicas y estratégias persuasivas en Chile colonial (1609-1709). Santiago: Lom, 2001.

4 Há, evidentemente, muitos relatos de milagres operados por intercessão de São Francisco Xavier (1506-1552) durante sua vida missionária no Oriente, depois de sua morte e após sua canonização. A difusão do culto a este santo, canonizado em 1622, juntamente com Inácio de Loyola, foi muito grande tanto na Europa quanto noutras partes do mundo, em particular no Oriente, graças ao empenho da Companhia de Jesus, da qual ele foi um dos fundadores. Estas constatações atiçam ainda mais nossa vontade de compreender este caso singular de malfadada tentativa de popularização de um santo que, noutros lugares, obteve a fervorosa devoção dos católicos. A bibliografia sobre o Apóstolo do Oriente é imensa. A primeira biografia foi a de TORSELLINO, Orazio. De vita Francisci Xaverii. Roma: ex Typographia Gabiana, 1594. Outra biografia clássica é a de LUCENA, pe. João de. História da vida do padre Francisco Xavier, e do que fizerão na Índia os mais religiosos da Companhia de Jesus. Lisboa: Pedro Craesbeeck, 1600. Para múltiplas referências documentais e bibliográficas sobre o santo e o culto que lhe foi/é rendido ver Brotéria. Cristianismo e cultura, vol. 163 (2006) - volume comemorativo do quinto centenário do nascimento de São Francisco Xavier. 


\section{I}

No santo cristalizam-se súplicas e esperanças de um coletivo religioso. ${ }^{5}$ Os fiéis estabelecem com ele uma relação quase contratual, tornando plausível o descumprimento de uma promessa cuja graça não foi alcançada. Porém, em se tratando de uma instituição como a Câmara e de um voto de tal magnitude no qual, diga-se de passagem, não aparecia nenhuma condicionante, é preciso considerar que outras variantes, a exemplo do possível engajamento com a ordem religiosa mais interessada em promover a causa do santo, tornariam mais complexa esta relação, dificultando a quebra da promessa. E assim, embora nada fosse mais incerto do que a intercessão de S. Francisco Xavier para livrar a cidade do mal da bicha, a Câmara de Salvador não retrocedeu em seu voto solene de elegê-lo padroeiro. Em carta enviada à Coroa, em julho de 1686, os vereadores mostravam sua firme intenção de cumprir com a sua parte, solicitando ao rei a aprovação de sua decisão, sem a qual não seria válida a escolha do padroeiro, nem se poderia realizar procissão, doravante, à custa do Conselho. Na correspondência há, aliás, uma ausência notável: não é feita menção alguma a qualquer milagre ou intercessão do Apóstolo do Oriente na ocasião. A lógica que guiou a manutenção do voto solene vinculou-se, neste caso, ao empenho da palavra dada e à expectativa de auxílio futuro. ${ }^{6}$ Isto não impediu que a Câmara gastasse somas consideráveis na realização da festa do padroeiro. Datam de 1697 os primeiros registros de despesas com a procissão encontrados até este momento da pesquisa. ${ }^{7}$ Naquele ano despendeu-se $90 \$ 600$ réis com a procissão, soma bem maior do que os $60 \$ 680$ réis gastos, no mesmo ano, com os festejos da aclamação de d. João IV. O quadro abaixo permite constatar a evolução, durante dez anos, das despesas com a procissão do padroeiro e, ao mesmo

5 DUPRONT, Alphonse. Du sacré. Croisades et pèlerinages. Images et langages. Paris: Gallimard, 1987, p. 535.

${ }^{6}$ Cf. Cartas do Senado 1684-1692, vol. 3, Salvador,... p. 25-26, carta de 20 de julho de 1686, "assentamos [...] tomassemos por protetor e Padroeiro da Cidade ao Gloriozo Apostolo do oriente Sam Francisco de Xavier para que nesta Cidade em outras occazioens que se podem offerecer alcance de Deos para ella e seus moradores aquelles favores (fl. 381) e mercez q para outras em Semelhantes Cazos impetrou com voto e promessa de que todos os annos em dez de Maio dia em que se fez este Acordo se lhe fassa festa com Procissão assim lho prometemos por voto no dito dia em que se lhe fez Procissão".

7 A Câmara organizou a festa, seguramente, a partir de 1689. O estado precário de conservação dos livros de pagamentos do Senado da Câmara impede, por vezes, que sejam encontrados registros como estes das despesas com as procissões reais. 
tempo, compará-la com aquelas feitas por ocasião de outras festas importantes celebradas na principal cidade da América portuguesa.

\begin{tabular}{ccccc} 
Ano & $\begin{array}{c}\text { São Francisco } \\
\text { Xavier }\end{array}$ & $\begin{array}{c}\text { Aclamação de d. } \\
\text { João IV }\end{array}$ & $\begin{array}{c}\text { Sto. Antonio } \\
\text { do Arguim }\end{array}$ & $\begin{array}{c}\text { Festa do Corpo de } \\
\text { Deus }\end{array}$ \\
\hline 1697 & $90 \$ 600$ & $60 \$ 680$ & - & $174 \$ 600$ \\
1698 & $101 \$ 380$ & $146 \$ 420$ & - & $245 \$ 800$ \\
1699 & $115 \$ 140$ & $108 \$ 600^{* * * * *}$ & - & $315 \$ 160 * * * *$ \\
1700 & $172 \$ 680$ & $61 \$ 100$ & $69 \$ 200$ & $307 \$ 100$ \\
1701 & $151 \$ 860$ & $139 \$ 440$ & - & $316 \$ 260$ \\
1702 & $180 \$ 380$ & $109 \$ 000$ & $115 \$ 080$ & $308 \$ 040$ \\
1703 & $181 \$ 800$ & $67 \$ 440$ & $104 \$ 080$ & $426 \$ 440$ \\
1704 & $196 \$ 680$ & $88 \$ 680$ & $92 \$ 600$ & $401 \$ 560$ \\
1705 & $220 \$ 600$ & $92 \$ 360$ & $83 \$ 760$ & $191 \$ 880 \mid 110 \$ 200$ \\
1706 & $195 \$ 600$ & $89 \$ 240$ & $120 \$ 600$ & $301 \$ 400$
\end{tabular}

Fonte: Livro de pagamentos do Senado da Câmara da Bahia - ACMS.

Os números acima não admitem dúvida: a Câmara de Salvador levou bastante a sério seu compromisso com a homenagem ao padroeiro, tornando-a a festa com o segundo maior dispêndio, atrás somente daquela do Corpo de Deus. Contudo, tais gastos não parecem ter sido suficientes para garantir popularidade ou aumento da devoção ao Apóstolo da Índia entre os habitantes da cidade da Bahia. Não temos conhecimento de nenhuma descrição pormenorizada da procissão e festa do padroeiro ao longo dos séculos XVII e XVIII. Sabemos, ao menos, que, como na festa do Corpo de Deus, danças e gigantes faziam parte do cortejo até o ano de $1750 .^{8}$ Esses costumes davam lugar a comentários pouco lisonjeiros por parte de viajantes menos habituados às formas de manifestação popular que marcavam certas procissões peninsulares e que também vieram para a América. ${ }^{9}$ Em 1696, ao desembarcar na Bahia às vésperas do dia de Corpus Christi, o jovem francês François Froger pôde assistir à procissão que, segundo ele,

$\overline{8}$ Cf. Arquivo Público da Bahia-APB. Livro de registros de correspondência do Senado da Câmara de Salvador para o rei. Cartas do Senado, fl. $57 v^{0}$ a $58 v^{\circ}$. Registo de huã Carta a s. Magd ${ }^{e}$. em que a camara lhe pede que os gastos que fazem os Taberneiros desta Cid ${ }^{\mathrm{e}}$. e Padros ${ }^{\text {. }}$ com a bandra nas prossiçoens, sejão applicadas a d $\mathrm{d}^{\mathrm{a}}$ despeza para os gastos miudos deste anno, digo deste $\mathrm{Con}^{\mathrm{co}}$.

9 É bom lembrar que muitas dessas manifestações foram consideradas abusivas e desde ao menos o século XV encontram-se ecos de tentativas de reprimi-las. Ver a respeito MARQUES, João Francisco. A renovação das práticas devocionais. In: AZEVEDO, Carlos Moreira. História religiosa de Portugal. Lisboa: Centro de Estudos de História Religiosa da Universidade Católica Portuguesa / Círculo de Leitores, vol. 2, 2000, p. 563-564. 
nesta cidade, é tão considerável pela prodigiosa quantidade de cruzes, relicários, de ricos ornamentos, de tropas armadas, de corporações de ofícios, de irmandades e de religiosos, quanto ridícula por seus grupos de mascarados, instrumentos e dançarinos que por suas posturas lúbricas atrapalham a ordem desta santa cerimônia. ${ }^{10}$

A ausência de descrições que ofereçam algum relato acerca da participação e engajamento da comunidade nos festejos pode ser tomada enquanto indício de que não se tratava de festa com grande apelo popular. A tentativa de dar maior visibilidade ao padroeiro, nos anos 1740 e 1750 - sobre a qual trataremos mais adiante-, parece corroborar esta ideia. Afinal, a autoridade diocesana não se daria tanto trabalho caso a festa já gozasse de popularidade e fervor devocional. Nesse sentido, é preciso ir em busca de vestígios que permitam compreender algumas das razões para a devoção não ter caído no gosto do público, malgrado o esforço da Câmara.

Vários fatores contribuíram para a impopularidade que, inicialmente, pode ser relacionada à falta de um milagre - fonte de potência e reconhecimento junto à comunidade de fiéis ${ }^{11}$ - proporcionado pelo padroeiro. ${ }^{12}$ Importa também lembrar que a data da festa do padroeiro não coincidia com o dia do santo - 3 de dezembro ${ }^{13}$-, tornando a celebração de 10 de maio um fato de memória que se vinculava mais ao voto solene da Câmara e à própria epidemia do que a um ato de devoção ao Apóstolo do Oriente, o que pode ter concorrido para a não recepção do culto. Cabe perguntar se não teria sido isto que levou a população a referir-se, no século XVIII, à festa de S. Francisco Xavier como "a festa da bicha”? ${ }^{14}$ Ora, se este raciocínio estiver correto, ainda que houvesse grande

${ }^{10}$ Lê-se no original: “ils furent voir la Procession du S. Sacrement, qui n'est pas moins considerable en cette Ville par une quantité prodigieuse de Croix, de châsses, de riches ornemens, de Troupes sous les armes, de Corps de Métiers, de Confrairies \& de Religieux, que ridicule par des troupes de Masques, d'Instrumens \& de Danseurs, qui par leurs postures lubriques troublent l'ordonnance de cette sainte ceremonie”. Cf. FROGER, François. Relation d'un voyage fait en 1695, 1696 \& 1697 aux Côtes d'Afrique, Détroit de Magellan, Brezil, Cayenne \& Isles Antilles, par une Escadre des Vaissezus du Rou, commandée par M. De Gennes... Paris: Chez Michel Brunet, 1698, p. 130-131.

${ }^{11}$ Ver o que diz sobre o assunto DUPRONT, Alphonse. Du sacré. Croisades et pèlerinages. Images et langages. Paris: Gallimard, 1987, p. 467-537. Ver também o excelente estudo de SIGAL, Pierre-André. L'homme et le miracle dans la France médiévale (XI ${ }^{e}$-XII- ${ }^{e}$ siècle). Paris: Cerf, 1985, especialmente, p. 9-15, 73-78 e 155-164.

12 Sobre o assunto ver SALES SOUZA, Evergton. São Francisco Xavier, padroeiro de Salvador. Gênese de uma devoção impopular. Brotéria. Revista de Cultura, v. 163, p. 653-670.

${ }^{13}$ Nos dias antecedentes ao 3 de dezembro era realizada novena na igreja dos jesuítas. Aliás, dois dos três sermões setecentistas baianos impressos dedicados a S. Francisco Xavier foram pregados no dia 3 de dezembro.

${ }^{14}$ Arquivo Histórico Ultramarino - AHU. Castro e Almeida, cx. 12, doc. 2.146. 
participação nas festividades - do que duvidamos muito -, ela não significaria necessariamente maior devoção da população ao padroeiro da cidade.

Problemas mais políticos do que religiosos também podem ter colaborado para a frieza devocional. Os desentendimentos entre o cabido e a Câmara sobre alguns aspectos relacionados à festa têm início muito cedo. Já em 1695, o cabido escrevia à corte:

Foi V. Mag.de servido mandar differir por carta de Novembro passado de 1694 aos motivos que este cabido tinha para não assistir a procissão de S. Francisco Xavier que a Câmara desta cidade costuma fazer todos os annos, como a V. Mag.de fazemos prezente: e ficamos entendendo q V. Mag.de he servido sem embargo das cauzas q reprezentamos, q acompanhemos e assistamos a dta. procissão e já assim o fizemos este anno em observância da carta de V. Mag.de. ${ }^{15}$

Em 1697, o mesmo cabido solicitava à Coroa que a Câmara iluminasse com velas a procissão, obrigando-a a fornecê-las aos capitulares e beneficiados da Sé. Na mesma petição, o cabido também pedia para que se lhe fossem pagos os devidos emolumentos por seus serviços durante os festejos que, ao que parece, estavam resumidos à procissão e missa celebrada na igreja dos jesuítas. ${ }^{16}$

Seguramente, os oficiais da Câmara não apreciaram estas intervenções do cabido. As dissensões em torno de precedências e privilégios parecem não se dissipar ao longo de todo o século XVIII. Nos anos de 1704 e 1711, a Câmara recorreu à Coroa para tentar impedir que os pregadores tomassem vênia ao cabido antes de ter início o sermão durante a missa festiva. ${ }^{17}$ Em 1731, em represália ao fato do pe. Manuel Ribeiro da Companhia de Jesus ter tomado vênia aos oficiais da Câmara antes de dar início ao seu sermão durante a missa comemorativa da expulsão dos holandeses da Bahia - solenidade realizada todos os anos, na Sé, no dia $1^{\circ}$ de maio -, o capitular da missa tratou de entoar o credo sem que o sermão pudesse ser pregado. O problema inicial com a Câmara estender-se-ia aos jesuítas que, na festa do padroeiro, realizada no subsequente 10 de maio, não permitiriam que um cônego cantasse a missa, como era costume nos anos anteriores. O cabido também se ausentou da procissão, causando, segundo o Senado da Câmara, grande escândalo. ${ }^{18}$ Esta situação de afastamento do cabido

\footnotetext{
${ }^{15}$ Cf. AHU. Luisa da Fonseca, cx. 31, doc. 3913. Carta do cabido de 22 de julho de 1695.

${ }^{16}$ Cf. AHU. Luisa da Fonseca, cx. 31, doc. 3913. Carta do cabido de 22 de julho de 1695.

${ }^{17}$ AHU. Castro e Almeida, cx. 12, doc. 2.143.

${ }^{18}$ Cf. AHU. Códices I, cód. 254, consulta do Conselho Ultramarino de 10 de maio de 1732, p.
} 
dos festejos do padroeiro permaneceu inalterada durante 22 anos. Somente em 1755, o cabido, após reconciliar-se com os jesuítas, voltaria a participar da festa. No ano seguinte, contudo, já eram enviadas à corte as queixas da Câmara e do cabido, reveladoras dos desentendimentos entre os dois corpos acerca dos privilégios e precedências de cada um. No dizer dos vereadores, a experiência mostrava "serem inconciliáveis dous corpos entre sy tão opostos como erão os Cônegos e Câmera desta Cidade”. ${ }^{19}$ Desentendiam-se por vênias e também por velas! Em 1695, como foi referido, o cabido pedia à corte que a Câmara distribuísse velas aos capitulares. Meio século depois, em 1756, reclamava da desatenção da Câmara, cujos oficiais nas procissões reais levavam brandões, enquanto que aos capitulares eram distribuídas velas como "a qualquer do povo", velas que não chegavam a ter "três quartas de pezo". ${ }^{20}$

Desentendimentos e confusões em festas e procissões nunca foram raros. ${ }^{21}$ Por si só, estes episódios não bastam para explicar o sucesso ou insucesso de

236. “despois sucedendo sucesivam.te a festa de S. Fr.co X.er que se custuma fazer na Igreja dos P.es da Comp.a a dez do d.o mes com procição q deve acompanhar o cabido sendo p.a isso avizado p.lo Procurador daquelle Senado na forma da Ordem de V. mag.de q se achava naq.le Archivo e constava da copea q com esta sobe as Reaes mãos de V. Mag.e faltou o d.o cabido àq.la obrigação de q rezultou fazerse a procição sem a sua asistencia cauzando esta falta mayor escandallo ao mesmo provo q estimulado della, e de outras semelhantes dezatençoens com q os R.dos Conegos procurão ultrajalos não deixa de se mostrar sentido e queixozo, e como os estimulos populares não se conformão com o seu sufrimento poderão seguirse gr.de dezordens q dezejão evitar pondose aos Reaes pés de V. Mag.e implorando se digne concederlhe licença p.a poderem fazer as festas q se costumão celebrar na d.a cathedral com despeza daq.le Senado em outra Igreja que V. Mag.e determinar ou for servido q elejão aonde senão falte com a urbanidade e a atenção devida àquelle Senado ao qual V. Mag.e tem feito tantas honras e m.ces que por ellas mereçe o seu auxilio p.a q fiquem seguros de toda a emulação".

${ }^{19}$ Cf. APB. Registros de correspondência do Senado da Câmara de Salvador para o rei. Cartas do Senado. 1742-1822, fl. $67 \mathrm{v}^{\circ}$ a 71.

${ }^{20}$ AHU. Castro e Almeida, cx. 12, doc. 2.143. Representação do cabido da Bahia, queixando-se das desconsiderações que lhe faziam o Juiz de Fora e Officiaes do Senado da Câmara..., 22 de junho de 1756.

${ }^{21}$ Cerimônias públicas como procissões e festas reais constituíam importantes momentos da vida política no Antigo Regime. Eram ocasiões em que cada parte constitutiva do corpo da nação procurava exibir ao conjunto da sociedade a proeminência do lugar ocupado, sinalizando por este meio a sua potência. Por esta razão eram comuns, nestes momentos, a exacerbação dos conflitos de precedências. A bibliografia sobre os usos políticos das cerimônias e ritos no Antigo Regime é vasta. Ver para o mundo português, entre outros, CURTO, Diogo Ramada. A cultura política em Portugal (1578-1642). Comportamentos, ritos e negócios. Tese de Doutorado, Faculdade de Ciências Sociais e Humanas da Universidade Nova de Lisboa, 1994; PAIVA, José Pedro. Etiqueta e cerimônias públicas na esfera da Igreja (séculos XVII-XVIII). In: JANCSÓ, István e KANTOR, Íris (orgs.). Festa. Cultura e sociabilidade na América portuguesa. São Paulo: Hucitec/Edusp/Fapesp/Imprensa Oficial, 2001, vol. I, p. 75-94; SANTOS, Beatriz Catão Cruz. 
uma festa devocional. Fosse o padroeiro santo que já gozasse de grande popularidade, nada disso, provavelmente, diminuiria o fervor da devoção dos fiéis. O Apóstolo do Oriente não era um desconhecido entre os católicos da Bahia, mas o santo, canonizado havia pouco mais de 60 anos, também não gozava de nenhuma devoção especial. ${ }^{22}$ Talvez tivesse maior reputação entre as gentes do mar que em suas viagens para o Oriente haviam aprendido a admirar e invocar o santo em horas difíceis. Não custa lembrar aqui que em 1682, Lorenzo Ortiz escrevia em El príncipe del mar San Francisco Javier, que "Todos los casos de su prodigiosa vida son raros, todos tiernos, todos admirables que los que le sucedieron en el mar navegando, o en bien y alivio de los que de él dependían. Fuera del mar raras son sus profecias, sus milagros, sus conversiones, su poder y los efectos de su caridad". ${ }^{23}$ Fora do mar também parecia minguar a devoção ao santo, ao menos nesta porção da América. Nenhuma confraria ou capela além é claro daquela existente na igreja dos jesuítas - havia sido consagrada ao Apóstolo do Oriente. Era preciso investir na construção de uma imagem positiva do santo, popularizar sua devoção entre os católicos da Bahia. Para tanto, na falta de grandes milagres realizados pelo santo padroeiro, fazia-se necessário

O corpo de Deus na América. A festa de Corpus Christi nas cidades da América portuguesa - século XVIII. São Paulo: Anna Blume, 2005; e PAES, Maria Paula Dias Couto. O teatro do controle: O domínio social e político na América portuguesa da primeira metade do século XVIII. Nuevo Mundo Mundos Nuevos, Coloquios, 2008, puesto en línea el 30 janvier 2008. URL: http://nuevomundo.revues.org/index21862.html. Consultado em 5 de novembro de 2008.

${ }^{22}$ Há uma notícia de devoção particular ao santo em outra região da arquidiocese baiana, mais precisamente na Ilha de Morro de São Paulo, “em que se acha levantada a Ermida do glorioso Apostolo das Índias S. Francisco Xavier sobre a praya, e porto, que dizem do Galeão, pela Costa interior do Rio, conrespondente à terra firme. Fundarão ao Santo esta Capellinha os moradores da mesma Ilha, e Morro por particular devoção, que tinhão ao Santo, e delle receberão especiaes favores, sendo hum, verem os circunvisinhos, e moradores das Fronteiras altas da terra firme, por muitos tempos daquelles princípios, todas as Segundas feiras, já alta noite, huma como procissão, formada de muitas luzes, ao que lhes parecia, verdes, ao redor da Capellinha, com admiração dos que as vião, que forão muitos, louvando juntamente a Deos nos juízos occultos, e altas providencias, com que por estas luzes lhes dava conhecimento claro dos muitos benefícios, de que lhe erão devedores, e das grandes mercês, de que pelos seus Santos os fazia participantes.” Cf. JABOATÃO, fr. Antonio de Sta. Maria. Novo Orbe serafico brazilico, ou Chronica dos frades menores da provincia do Brazil, por Fr. Antonio de Santa Maria Jaboatão, impressa em Lisboa em 1761, e reimpressa por ordem do Instituto Historico e Geographico Brazileiro. Rio de Janeiro, 1858, 2 volumes, p. 104.

${ }^{23}$ ORTIZ, Lorenzo. El principe del mar San Francisco Xavier de la Compañia de Jesus, Apostol de el Oriente y patron de sus navegationes... Brusselas: por Francisco Foppens, 1682, apud OSSWALD, Maria Cristina. S. Francisco Xavier no Oriente - aspectos de devoção e iconografia. In: São Francisco Xavier: nos 500 anos do nascimento de São Francisco Xavier: da Europa para o mundo 1506-2006. Porto: Universidade do Porto, p. 133-134. 
reinventar a memória dos eventos de 1686, no intuito de torná-lo responsável por um grande milagre em terras baianas.

\section{II}

É praticamente impossível precisar a data em que tem início a reconstrução da memória dos eventos de 1686. Os vestígios do tempo permitem ver que em 1689, ano em que S. Francisco Xavier foi confirmado padroeiro principal da cidade da Bahia, ainda não havia menção sobre sua intercessão na epidemia que assolara a cidade anos antes. O arcebispo d. frei Manuel da Ressurreição, ao confirmar a eleição do padroeiro, lembrava que a primeira eleição ocorrera numa época em que a cidade se encontrava "afflicta com as pestilenciaes doenças, que em seus moradores se havião ateado”. Sem mencionar qualquer intercessão miraculosa naquela ocasião, ao tratar da confirmação da nova eleição que se fazia do padroeiro, o mesmo arcebispo escrevia:

E desejando Nós condescender com a louvável devoção do dito Senado, e mais moradores; e outro sim confiando na misericórdia Divina, que pela intercessão, e merecimentos deste seu tão valido Servo, se compadecerá deste seu povo, aplacando a justa ira a que o tem provocado os peccados dos homens, dignando-se concedernos o benefício da desejada saúde, e temperança dos ares sauddaveis, que por tantos annos se lograrão em todo este Estado. ${ }^{24}$

Portanto, ainda em 1689, a escolha do padroeiro reportava-se à confiança da comunidade em futuras intercessões do santo, mas não à eficácia do recurso ao mesmo por ocasião do mal da bicha que, em 1686, ceifou tantas vidas.

Em Pernambuco, onde a epidemia de febre amarela teve início nos idos de 1685, a doença também fez muitas vítimas. Ao tornar-se endêmica parece ter, durante alguns anos, atacado a população com maior intensidade do que na Bahia. Em 1692, o médico João Ferreyra da Rosa, em seu Tratado único da constituição pestilencial de Pernambuco, lembra que a epidemia havia se estendido à Bahia, mas não faz qualquer menção à devoção a S. Francisco Xavier como meio útil para as pessoas livrarem-se daquele mal. Quando se reporta aos remédios sobrenaturais diz:

${ }^{24}$ Carta pastoral de d. Manuel da Ressureição, de 16/4/1689. In: Rito Ecclesiastico, que ao Apostolo do Oriente S. Francisco Xavier he devido na Cidade de S. Salvador Bahia de Todos os Santos como o seu Protector, e Principal Patrono. Lisboa: na Officina Patriarcal de Francisco Luiz Ameno, 1756. 
Seja fervorosa com a reforma em nós a intercessão da Santíssima Virgem Maria Mãy de Deos para com a Divina Majestade; \& invoquemos também todos os Santos, \& particularmente a Sam Sebastiam \& Sam Roque, que são Advogados da peste. ${ }^{25}$

Nas Constituições do arcebispado da Bahia, redigidas em 1707, mas publicadas somente em 1719, fazia-se menção ao feriado de 3 de novembro na cidade da Bahia em razão de ser o dia do seu padroeiro, e também ao fato da procissão ser organizada pela Câmara, não necessitando, portanto, de autorização da autoridade ordinária para a sua realização. ${ }^{26} \mathrm{O}$ dia 10 de maio, entretanto, aparece no índice dos dias feriados da Relação e Auditório Eclesiástico da Bahia, designado como "a festa do voto, e a procissão real a S. Francisco Xavier". ${ }^{27}$ Na primeira edição das Constituições foi publicado também um Catálogo dos bispos e arcebispos da Bahia, escrito, provavelmente, em 1718. Nele, relata como obra de d. Manuel da Ressurreição a eleição ${ }^{28}$ e confirmação de S. Francisco Xavier como padroeiro da cidade, lembrando que "infestada a Bahia de algumas calamidades, cujo remédio se desesperava ao aperto, o foram buscar bem longe, e lá muito além do Cabo de Boa Esperança”. Por esta razão,

Todas as vezes que depois do período de um ano, tornar a amanhecer à Bahia o dia 10 de maio, se deve ela lembrar que aquele é o dia da sua ressurreição, porque a esta deve a assistência de um santo, que para se parecer com o sol matutino da ressurreição, lá está descansando naquela região, onde a aurora tem seu tálamo. ${ }^{29}$

O texto envolto num claro artifício retórico, pois a palavra ressurreição era usada, sobretudo, em função do nome do prelado ao qual se referia em seu catálogo encomiástico, não deixa de sugerir uma relação de causalidade entre a calamidade - a bicha - e o remédio que revivifica - a intercessão do santo.

\footnotetext{
${ }^{25}$ ROSA, João Ferreyra da. Tratado único da constituição pestilencial de Pernambuco offerecido a El Rey N. S. por ser servido ordenar por seu Governador aos Médicos da América, que assistem aonde há este contagio, que o compusessem para se conferirem pelos coripheos da Medicina aos dictames com que he trattada esta pestilencial febre. Lisboa: na Officina de Miguel Manescal, 1694, p. 58.

${ }^{26}$ Cf. Constituições primeiras do arcebispado da Bahia..., §§ 374 e 491.

${ }^{27}$ Cf. Regimento do Auditório ecclesiastico do arcebispado da Bahia..., publicado juntamente com as Constituições primeiras do arcebispado da Bahia..., p. 5.

${ }^{28}$ Como se sabe, devido às exigências da Congregação dos Ritos, foi feita nova eleição do padroeiro, em 1689, para em seguida o arcebispo confirmá-lo.

${ }^{29}$ Cf. Catálogo dos bispos que teve o Brasil até o ano de 1676, em que a catedral da cidade da Bahia foi elevada a metropolitana, e dos arcebispos que nela tem havido com as notícias que de uns e outros pode descobrir... In: Constituições primeiras do arcebispado da Bahia..., p. 25-26.
} 
Alguns anos depois, o texto de Rocha Pita expressa a reconstrução da memória dos eventos de 1686 num estágio mais avançado. Dos testemunhos que conhecemos, o de Rocha Pitta é o primeiro a estabelecer uma relação direta entre o fim da epidemia e a intercessão do Apóstolo do Oriente. Em sua História da América portuguesa - cuja redação terminou por volta de 1725 -, conta que, ouvindo as deprecações do santo, Deus aplacou sua ira contra os pecados dos moradores desta cidade e o mal foi perdendo força, contaminando um número cada vez menor de pessoas e raramente levando-as à morte. ${ }^{30}$ Em sua narrativa, a eleição do padroeiro torna-se uma obrigação contraída pela cidade da Bahia em virtude do patrocínio "que achara no glorioso S. Francisco Xavier". ${ }^{31}$ Embora, a partir deste testemunho, seja possível pensar que na década de 1720 estava em marcha a reconstrução da memória da epidemia de 1686, é preciso notar que noutro importante escrito do mesmo período, o Compêndio narrativo do peregrino da América, faz-se menção à bicha apenas enquanto doença que provocou a morte de muitas pessoas "sem lhes poderem os médicos acertar com o remédio, por ser castigo dado por Deus, e merecido por pecados” que teriam atiçado sua ira, silenciando toda e qualquer intercessão miraculosa do padroeiro. ${ }^{32}$

Em 1742, na missa de 10 de maio, o jesuíta Francisco de Almeida proferiu um Sermam de S. Francisco Xavier. Seguramente não foi a primeira vez em que os fatos ocorridos na epidemia de 1686 constituíram objeto de um sermão pregado no dia em que se celebrava o voto solene da Câmara ao Apostolo do Oriente. Mas, até o presente momento, desconhecemos a existência de outro sermão proferido nos festejos de 10 de maio que tenha sido publicado anteriormente. O que mais importa, contudo, é assinalar uma evidência: a década de 1740 inaugura uma nova fase na construção da memória sobre a epidemia e o papel do santo padroeiro naquela ocasião. O primeiro dado que retém a atenção do historiador surge já no título: Sermam de S. Francisco Xavier, protector da cidade da Bahia, na solemnidade anniversaria, com que o festeja o nobilíssimo Senado da Câmera, pelo beneficio, que fez a todo Estado do Brasil, livrando-o

\footnotetext{
${ }^{30}$ ROCHA PITTA, Sebastião da. História da América portuguesa. Bahia: Progresso Editora, 1950, l. 7, §§ 42 e 43.

${ }^{31}$ Idem, § 44.

${ }^{32}$ Cf. PEREIRA, Nuno Marques. Compêndio narrativo do peregrino da América. Rio de Janeiro: Academia Brasileira de Letras, $7^{\mathrm{a}}$ ed., 1988 ( $1^{\mathrm{a}}$ ed., 1728), p. 147. O silêncio é ainda mais significativo por tratar-se de uma obra de piedade e devoção.
} 
da peste chamada vulgarmente a bicha. Ele não deixa dúvida sobre o santo ter livrado a cidade da epidemia. Mais do que isso: o Apóstolo do Oriente livrara todo o Brasil da bicha. No sermão cujo tema é In nomine meo serpentes tollent (Marcos, 16), o jesuíta traça paralelos entre o titular - Jesus, o Salvador -, e o padroeiro da cidade da Bahia, pretendendo mostrar "São Francisco Xavier por desempenho de Christo salvador da Cidade do Salvador”. ${ }^{33}$ Após aludir aos trabalhos missionários do santo no Oriente, promovendo a conversão salvação, diria o pregador - de tantas almas em nome do Cristo, compara-os à salvação dos corpos que promoveu "quando no anno de 1686 salvou a Bahia, ou Cidade do Salvador daquella pestilente epidemia”. ${ }^{34} \mathrm{O}$ sermão ainda retoma várias vezes o tema da eficaz intercessão do Apóstolo do Oriente na epidemia de 1686. Em certa altura, toma emprestado a João Ferreyra Rosa a descrição do eclipse que antecedera a epidemia que viria a assolar Pernambuco, Bahia e outras regiões da América portuguesa. Em seguida, demonstra seu acordo com a ideia de que tais enfermidades eram normalmente precedidas por estes sinais que se constituíam também em agentes propagadores da doença, na medida em que se cria que o ar poderia ser contaminado pelos astros e, em particular, pelos eclipses do sol e da lua. ${ }^{35}$ Mas, diz o pregador, “como do céu vinhão os pronosticos do contágio, no Ceo se buscarão também as indicaçoens do remédio". Iguaraçu em Pernambuco recorreu a Cosme e Damião "e conseguio o remédio com tanta felicidade, que ferindo a peste o vasto corpo daquella Capitania, não pode infestar a pequena porção de terra”. O Rio de Janeiro valeu-se de São Sebastião, mas as flechas daquele famoso santo antipeste nada operaram para livrar a cidade daquele mal. Já a Bahia

como cabeça, onde reside o entendimento, discorreo no remédio com mayor acerto. Como via que aquella nevoa, ou aranha, apontava para a esfera do Sol, não buscou o sol em Geminis, e muito menos no Sagittario. Buscou o Sol no mesmo Sol, o Sol divino na

\footnotetext{
${ }^{33}$ ALMEIDA, Francisco de. Sermam de S. Francisco Xavier, protector da cidade da Bahia, na solemnidade anniversaria, com que o festeja o nobilíssimo Senado da Câmera, pelo beneficio, que fez a todo Estado do Brasil, livrando-o da peste chamada vulgarmente a Bicha. Recitado na Igreja do Real Collegio de Jesu a 10 de mayo de 1742. Com o Sacramento exposto e dedicado por seu author o R. P. M. Francisco de Almeida, da Companhia de Jesu ao Senhor Antonio Joseph Victoriano Borges da Fonseca, capitão de Infantaria do Presídio de Olynda, e Mestre em Artes pelos Estudos Geraes da mesma cidade. Lisboa: na officina dos Herdeiros de Antonio Pedrozo Galram, 1743, p. 4. ${ }^{34}$ Id., p. 4.

${ }^{35}$ Ver ROSA, João F. Tratado único da constituição pestilencial de Pernambuco..., p. 11 e ALMEIDA, Francisco de. Sermam..., p. 6-7.
} 
intercessão do Sol do Oriente. E não se enganou: porque feitas as primeiras suplicas, o Sol de justiça tornou-se logo em Sol de misericórdia. ${ }^{36}$

Nota-se o salto dado na reconstrução dos eventos de 1686. Não só o santo livrou a cidade da peste como o fez imediatamente, tão logo lhe foram dirigidas as primeiras súplicas. Naquilo que poderia ser entendido como um programa para propagar a devoção ao santo padroeiro, é publicado, em 1747, o sermão proferido pelo padre Simão Marques na celebração da missa dedicada ao santo em 3 de dezembro de 1745. Nenhuma referência é feita ao milagre operado pelo missionário navarrês na epidemia de 1686, concentrando-se o pregador na abordagem de aspectos de sua vida e dos prodígios que realizou nas Índias orientais. O que chama a atenção é o paralelo traçado logo nos momentos iniciais da prédica entre o Salvador e o Apóstolo do Oriente, ao lembrar que na cidade “aonde emparelhão em ser padroeyros S. Francisco Xavier, e São Salvador, com propriedade se attribue também a Xavier a excellencia de Salvador”. ${ }^{37}$ Além de marcar a repetição de um tema abordado por seu confrade no sermão referido anteriormente, a insistência sobre o assunto parece antecipar o problema da confusão entre prerrogativas do titular e do padroeiro que, alguns anos mais tarde, viria a ser resolvido, mediante consulta do arcebispo d. José Botelho de Mattos à cúria romana.

Na década de 1750, há um notório esforço do arcebispo para tornar o padroeiro mais popular. Em 1753, dirigiu à Santa Sé uma súplica na qual propunha que fossem dirimidas as dúvidas acerca do culto devido ao titular e ao padroeiro da cidade da Bahia, bem como sobre a menção do nome do santo padroeiro na oração A cunctis da missa. ${ }^{38}$ A Declaração da Congregação dos Ritos, dada em fevereiro de 1754, confirmou ser o Salvador titular e não patrono ou padroeiro

\footnotetext{
${ }^{36}$ ALMEIDA, Francisco de. Sermam..., p. 8.

${ }^{37}$ MARQUES, Simam. Sermam do Grande Apóstolo do Oriente S. Francisco Xavier, padroeyro da cidade de S. Salvador da Bahia de todos os Santos. Pregou-o no real Collegio da Companhia de Jesus, da mesma cidade da Bahia, em 3 de dezembro de 1745, sendo Reytor actual do mesmo Collegio o M. R. P. M. Simam Marques... Lisboa: na Officina de Antonio da Silva, 1747, p. 2. Agradeço a Pablo Iglesias A. Magalhães a gentileza de trazer para mim fotocópias deste sermão e do anteriormente citado, proferido pelo pe. Francisco de Almeida.

${ }^{38}$ Oração A cunctis é aquela que inicia a oração colecta. Nela o celebrante invoca a proteção da Virgem, dos apóstolos Pedro e Paulo, dos santos padroeiros da diocese e da igreja onde a missa é celebrada. Ver GUILLOIS, Ambroise. Explication historique, dogmatique, morale, liturgique et canonique du catechisme avec la reponse aux principales objections tirées des sciences contre la religion. Paris: Julien, Lanier et Cie., 1853, v. 4, p. 263-265.
} 
principal da cidade da Bahia e também se conformou à opinião de que o nome do padroeiro e não o do titular deveria ser pronunciado na oração A cunctis. Em agosto do mesmo ano, o arcebispo publica uma pastoral na qual comunica a todos os sacerdotes a resolução das mencionadas dúvidas e informa que doravante os sacerdotes soteropolitanos deverão invocar o nome do padroeiro, S. Francisco Xavier, e não o do titular, após mencionar os nomes dos apóstolos Pedro e Paulo no referido momento litúrgico. ${ }^{39}$ Ora, a menção do padroeiro em cada missa celebrada nas igrejas da cidade poderia, sem dúvida, fortalecer uma devoção que até ali, ao que tudo indica, ainda não havia caído no gosto popular. Mais do que nunca, era importante reforçar a imagem do santo entre os fiéis baianos, rememorando os fatos que deram lugar à sua legítima eleição como patrono de Salvador. Neste sentido, na própria pastoral, dirigida ao clero secular e regular, Botelho de Mattos afirmava que

Porquanto o Senado da Câmera em gratificação do grande beneficio, que achou na sua sagrada protecção livrando a este povo da horrorosa epidemia, que houve no anno de 1686 com morte de innumeraveis pessoas, a que erão inúteis todos os remédios humanos, o tomou, e elegeo por Protector e Padroeiro principal desta Cidade... ${ }^{40}$

A versão de que o santo livrara a cidade da epidemia já lançada pelo pe. Francisco de Almeida em seu sermão, em 1742, ganhava agora o respaldo da própria autoridade arquiepiscopal. Como é sabido, após a publicação do texto de Lorenzo Valla (1440) apontando a falsidade do édito de Constantino, a erudição foi ganhando um espaço cada vez mais destacado no mundo moderno, modificando radicalmente os critérios que atestavam a autenticidade de um documento ou registro, antes dependentes, sobretudo, da autoridade da qual emanava. $\mathrm{O}$ avanço da erudição, contudo, não nos deve fazer duvidar de que, no mundo português de meados do século XVIII, a palavra de um arcebispo poderia contribuir para legitimar uma determinada versão da história, ainda mais quando se tratava de fatos envolvendo problemas relacionados à religião.

Para além da pastoral de 4 de agosto, provavelmente às instâncias do arcebispo, celebrou-se a missa de São Francisco Xavier, do dia 3 de dezembro daquele ano de 1754, na Catedral e não na igreja dos jesuítas como de hábito.

\footnotetext{
${ }^{39}$ Cf. MATTOS, José Botelho de. Pastoral do excelentíssimo e reverendíssimo senhor Arcebispo da Bahia... em que declara ao Apóstolo do Oriente S. Francisco Xavier por protector, e principal Patrono da cidade de S. Salvador e seus subúrbios. Publicada em 4 de agosto de 1754.

${ }^{40}$ Idem.
} 
$\mathrm{Na}$ ocasião, foi pregado um sermão, seguramente encomendado por Botelho de Mattos, pelo mesmo pe. Francisco de Almeida que doze anos antes havia feito a prédica comemorativa do dia do Apóstolo do Oriente, na igreja dos jesuítas. ${ }^{41}$ Se naquela ocasião o pregador mal tocou em assuntos locais, desta vez foi bem diferente. Dividiu o sermão em duas partes. Na primeira tratou das qualidades de S. Francisco Xavier para ser protetor e principal patrono da cidade. Na segunda parte, bem mais dilatada do que a outra, trouxe "à memória" os eventos que levaram à eleição do padroeiro em Salvador. Como o próprio predicador confessa, os assuntos tratados eram menos panegíricos que históricos. Interessa-nos, em particular, a segunda parte do sermão, que principia pela relação de exemplos da eficácia antipeste do santo, sendo mencionados os casos de Malaca, Palermo, Nápoles e Roma. Em seguida, é feita referência a algumas das cidades e regiões (como é o caso da Cristandade Oriental) que têm no santo seu padroeiro. Por fim, o pregador rememora a epidemia na Bahia e exalta a intercessão milagrosa do Apóstolo do Oriente.

Corria o anno de 1686, quando entrou nesta Bahia hum Barco de Pernambuco, e nelle o terrível contagio, a que derão o nome, que ainda conserva, de Bicha. Inficionou-se o ar, e despovoou-se a terra. Huns morrião com o remédio da lanceta, outros com os medicamentos, que a Arte receitava: e muitos sem remédio, porque nem tempo, nem Arte havia para lho applicar. Dos mesmos Médicos, a quem o mal não respeitou, faltarão alguns. Os sinos já não dobravão, por não apressar a morte aos que estavão em agonia: e dos mortos erão muitos, os que de huma vez se enterravão na mesma cova. Muitas das casas, que agora habitamos, ficarão sem moradores, e fechadas: e as Praças, e principaes ruas, por onde andamos, desertas, e sem gente. O Santíssimo, quando sahia por viatico aos enfermos, não havia quem o acompanhasse, bem que suppria essa falta, quanto era possível, o Illustrissimo, e Excelentíssimo Márquez das Minas, que então governava; e com piedade igual ao grande animo, e valor, de que foy dotado, todas as vezes, que o

${ }^{41} \mathrm{O}$ jesuíta iniciou sua prédica lembrando que estava em casa alheia e que não tinha liberdade para escolher tese ou "formar discursos". Cf. MARQUES, Simão. Sermão do grande apostolo do Oriente S. Francisco Xavier Protector, e Principal Patrono da Cidade de Salvador, Bahia de Todos os Santos. Recitado na Cathedral da mesma Cidade em 3 de Dezembro de 1754, estando o Senhor exposto. Por seu Author o M. R. P. M. Simão Marques da Companhia de Jesus, em occasião, que o Excellentissimo, e Reverendissimo Senhor D. Joseph Botelho de Mattos... recebeo da Sagrada Congregação dos Ritos a declaração de duas duvidas, que o mesmo Senhor Arcebispo representou ao Santissimo Padre Benedicto XIV. Acerca do rito Ecclesiastico, que na Bahia he devido a S. Francisco Xavier, como a seu Protector, e Principal Patrono, p. 19. 
senhor sahio fora na maior fúria da Bicha, sempre o acompanhou até o lugar mais intimo, onde jazião os apestados: que talvez por isso o privilegiou, e não ferio a peste.

Reduzida a tão lastimoso estado a Bahia, que quasi se desconhecia a si mesma, que lhe restava, senão recorrer ao Ceo? Assim o fez: multiplicou supplicas, e rogativas a Deos, e aos Santos, orando todos com aquelle fervor, e vehemencia de affectos que a mesma necessidade ensina: mas o ar maligno, como dantes, e a mortalidade a não diminuir: até que por último occorreo, ou inspirou o Ceo, se procurasse applacar a ira de Deos por intercessão de seu Servo S. Francisco Xavier, que tirado do Altar, onde era venerado, e mostrado em Procissão as principaes ruas, e praças desta Cidade, fez termo a epidemia: Pestem sevissimam confestim extinxit. ${ }^{42}$

A narrativa acima pode muito bem ser considerada o ponto de chegada do processo de construção da memória da intercessão do santo jesuíta à época da Bicha. A elementos cuja veracidade histórica é possível comprovar - tais a origem pernambucana da epidemia, a suspensão do dobre fúnebre dos sinos e a piedade demonstrada pelo então governador, o marquês das Minas - misturavase o relato de uma intercessão miraculosa e imediata do santo invocado, fato inteiramente desconhecido dos sobreviventes da epidemia. ${ }^{43}$ Mesclava-se o histórico ao panegírico para dotar o padroeiro de uma memória que pudesse viver nas mentes e nos corações dos fiéis soteropolitanos, fazendo-os abraçar aquele que um dia, segundo o pregador e o prelado arquidiocesano, os havia livrado de tão terrível peste.

Por corolário das festividades havidas em 1754, o arcebispo mandara publicar um opúsculo no qual figuravam a súplica que havia encaminhado a Roma a Declaração da Congregação dos Ritos, a sua Instrução Pastoral de 4 de agosto de 1754, o referido sermão do pe. Simão Marques, além de cópias da Provisão de d. Pedro II, de 1687, dando seu acordo ao voto da Câmara de tomar a S. Francisco Xavier por padroeiro, e do breve da Congregação dos Ritos, de 1688, aprovando a eleição do padroeiro. A publicação seria retardada devido ao terremoto de Lisboa, no qual se perderam as cópias que para lá tinham ido. Novas vias foram enviadas em 1756, quando, enfim, saiu impresso o Rito eclesiástico que

\footnotetext{
${ }^{42}$ Idem, p. 26-27.

${ }^{43}$ Para uma narrativa pormenorizada dos eventos da epidemia de 1686 na Bahia ver SALES SOUZA, Evergton. São Francisco Xavier, padroeiro de Salvador. Gênese de uma devoção impopular. Brotéria. Revista de Cultura, v. 163, p. 653-670.
} 
ao apóstolo do Oriente S. Francisco Xavier he devido na Cidade de Salvador Bahia de Todos os Santos como a seu protector, e principal patrono. ${ }^{44}$

Nunca antes um arcebispo da Bahia havia se engajado tanto na tentativa de dar maior ênfase ao culto ao padroeiro da cidade. O empenho de d. José Botelho de Mattos tem, sem dúvida, estreita relação com sua devoção particular ao santo, confessada no prólogo Ao leitor, do Rito eclesiástico, em que diz ser aquele papel "hum testemunho authentico da cordialissima devoção que proffesa ao Apostolo do Oriente”. S. Francisco Xavier também seria lembrado em seu testamento, no qual ordenava a celebração de cinco missas ao santo, como um daqueles de sua especial devoção, na Igreja de Nossa Senhora da Penha, onde fora sepultado. ${ }^{45}$

\section{III}

Ao leitor mais atento não deve ter passado despercebido que a reconciliação do cabido com os jesuítas, referida noutra parte deste artigo, ter-se-ia dado justamente em 1754. O arcebispo deve ter desempenhado um importante papel naquele momento e a celebração da missa de S. Francisco Xavier na catedral, com sermão pregado por um padre da Companhia de Jesus, determinou, seguramente, o fim do dissenso entre as duas instituições. A participação do cabido na festa de 10 de maio de 1755 e a celebração da missa na igreja do Colégio dos Jesuítas por um capitular coroaram a reconciliação. Contudo, como já vimos, permaneceram os problemas e malquerenças entre cabido e Câmara, estes dois corpos tão "inconciliáveis entre sy". A permanência de tais querelas retirava um pouco do brilho que o arcebispo desejava dar aos festejos do padroeiro, mas algo ainda mais determinante para o futuro da devoção teria lugar alguns anos mais tarde. Com efeito, a expulsão da Companhia de Jesus de todo o Império português criou um vazio do ponto de vista da promoção devocional ${ }^{46}$

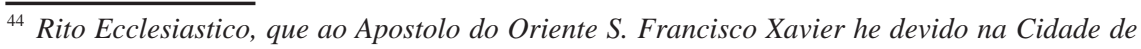
S. Salvador Bahia de Todos os Santos como o seu Protector, e Principal Patrono. Lisboa: na Officina Patriarcal de Francisco Luiz Ameno, 1756.

${ }^{45}$ Cf. ALENCAR, Carlos Augusto Peixoto d'. Roteiro dos bispados do Brasil, e dos seos respectivos bispos, desde os primeiros tempos coloniaes até o presente, pelo Padre Carlos Augusto Peixoto d'Alencar, parocho collado da freguezia da capital da província do Ceará, e Director Geral da Instrucção Pública da mesma província. Ceará: Typ. Cearense, 1864, p. 63. O autor transcreve na íntegra o assento de óbito de d. José Botelho de Mattos.

${ }^{46}$ Infelizmente, não é possível ainda responder muitas questões. Dentre elas, uma nos parece particularmente importante: continuou, após a expulsão dos jesuítas, a realização da novena e festa do santo no dia 3 de dezembro? Ora, a descontinuidade da festa constituiria, sem dúvida, 
e, possivelmente, novas dificuldades do ponto de vista das celebrações em homenagem ao padroeiro, pois a Câmara teve que se conformar com a atuação do cabido nas festividades.

Embora as despesas com a festa fossem mantidas no mesmo patamar que se verificava antes da expulsão dos jesuítas (como se vê na tabela abaixo), é forçoso constatar que não havia mais como o Senado da Câmara insistir numa estratégia de autopromoção através do abrilhantamento da festa e da demonstração de sua precedência fosse por meio das vênias ou pelo tamanho das velas a serem portadas ao longo do cortejo. Talvez tivesse passado pela cabeça de muitos oficiais que não valia a pena querelar para obter maior visibilidade na celebração de um santo pertencente a uma ordem proscrita.

\begin{tabular}{cl} 
Despesas com os festejos de S. Francisco Xavier \\
\hline Ano & Despesa \\
1754 & $238 \$ 820$ \\
1755 & $222 \$ 670$ \\
1756 & $234 \$ 900$ \\
1757 & $261 \$ 800$ \\
1758 & $262 \$ 240$ \\
1759 & $251 \$ 920$ \\
1760 & Dado não encontrado \\
1761 & Idem* \\
1762 & $236 \$ 725$ \\
1763 & $239 \$ 350$ \\
1764 & Dado não encontrado \\
\hline 1765 & $263 \$ 100$ \\
\hline
\end{tabular}

* A ausência de registro das despesas com a festa dos anos 1760 e 1761, não deve dar lugar a conclusões precipitadas a respeito de uma possível suspensão da festa. Não encontramos até aqui qualquer sinal de que elas tenham deixado de ser realizadas.

Fonte: Livros de pagamentos do Senado da Câmara da Bahia - ACMS.

um fator de definhamento da devoção ao santo. Tanto mais que a celebração de 10 de maio, como já foi dito, estava mais ligada à memória da epidemia do que a uma especial devoção. 
Anos mais tarde, em 1777, chega à corte a notícia de uma quizila a respeito da cera dada ao cabido, mas estava relacionada à procissão do Corpo de Deus. Sobre aquela de S. Francisco Xavier nenhuma representação do cabido ou da Câmara parece ter subido ao Conselho Ultramarino após fins da década de 1750. Na verdade, após todo o empenho na reconstrução da memória dos eventos de 1686, os eventos da conturbada conjuntura 1758-1760 inviabilizariam o sucesso da iniciativa de dotar o padroeiro de Salvador de uma verdadeira e popular devoção. Seria preciso esperar praticamente um século para que, em decorrência de uma outra epidemia - desta vez de cholera morbus -, a arquidiocese tentasse reabilitar o culto ao santo padroeiro.

Recebido: janeiro/2009 - Aprovado: outubro/2009. 